(С) Н.Н. Захарьева, И.Д. Коняев, И.В. Абдрахманова

\title{
ВЛИЯНИЕ ПСИХОЭМОЦИОНАЛЬНОГО НАПРЯЖЕНИЯ НА ПСИХОФИЗИОЛОГИЧЕСКИЕ ХАРАКТЕРИСТИКИ И ФИЗИЧЕСКИЕ КАЧЕСТВА ТАНЦОРОВ И ТАНЦОВЩИЦ ВЫСОКОЙ КВАЛИФИКАЦИИ
}

\begin{abstract}
Проведено обследование 96 спортсменов-танцоров высокой квалификации (50 мужчин и 46 женщин) в подготовительном периоде спортивной подготовки. По результатам анкетирования и психофизиологического тестирования с использованием тестов: TMAS (Taylor manifest anxiety scale), Ч.Д. Спилбергер - Ю.Л. Ханин, «Индивидуальная минута» таниоры распределены по психоэмочиональному напряжению на 3 группь: Grl - низкий уровень (n=40; муж - 24 чел. и жен - 16 чел.); Gr2 - средний уровень (n=39; муж - 19 чел. $и$ жен - 20 чел.); Gr3 - высокий уровень (n=17; муж - 7 чел. и жен - 10 чел.). Для дифференцирования уровней психоэмочионального напряжения танцоров высокой квалификачии без учета половых различий рекомендованы психофизиологические тесты:: TMAS; «Реакиия на звук правой рукой»; «Простая зрительно-моторная реакция» и тест физической работоспособности $P W C_{170^{\circ}}$ У танцовщиц-женщин с различным уровнем психоэмоционального напряжения установлены достоверные отличия в группах сравнения в тестах: "Реакциия на звук», выполненная правой рукой ( $><0,001)$; «Воспроизведение временного интервала со звуковым сигналом», «Оченка величины углов» $(p<0,05)$. У танцоров-мужчин с различным уровнем психоэмочионального напряжения установлены достоверные отличия в тестах: $P W C_{170}(p<0,05)$ и теппинг тесте (1-я и 2-я попытка). Танцуоры, имеющие высокое психоэмоциональное напряжение, имеют самые низкие значения физической работоспособности в группах сравнения, что может обуславливать их низкую $р$
\end{abstract}

Ключевые слова: спортивные бальные танцы, умственная работоспособность, физическая работоспособность, функииональное состояние, пространственно-временные характеристики нервной системы, танц̧оры, танцฺовщчиць

Захарьева Наталья Николаевна - профессор кафедры физиологии Федерального государственного бюджетного образовательного учреждения высшего образования «Российский государственный университет физической культуры, спорта, молодежи и туризма (ГЦОЛИФК)». (Москва, Сиреневый бул. 4, стр.4). E-mail: zakharyeva.natalia@mail.ru

Коняев Илья Дмитриевич - аспирант кафедры физиологии Федерального государственного бюджетного образовательного учреждения высшего образования «Российский государственный университет физической культуры, спорта, молодежи и туризма (ГЦОЛИФК)». (Москва, Сиреневый бул. 4, стр.4). E-mail: Ilya.konyaev@mail.ru

Абдрахманова Ирина Владимировна - доцент кафедры анатомии и физиологии ФГБОУ ВПО «Волгоградская государственная академия физической культуры». (Волгоград, просп. им. В.И. Ленина, 78). E-mail: abdr-iren@yandex.ru 
Ссылка при цитировании: Захарьева Н.Н., Коняев И.Д., Абдрахманова И.В. Влияние психоэмоционального напряжения на психофизиологические характеристики и физические качества танцоров и танцовщиц высокой квалификации // Вестник антропологии, 2021. № 4. С. 381-395.

\section{Введение}

Танцевальный спорт - зрелищный, яркий и красивый. Это симбиоз спорта и искусства. Однако, за видимой легкостью исполнения танцевальных фигур, скрывается многолетняя физическая подготовка и колоссальное психологическое напряжение (Возрастная и педагогическая психология 1979). В научной литературе есть мнение ряда авторов, что для победы в спортивных соревнованиях, при занятиях спортивными бальными танцами, большое значение играет эмоциональная устойчивость, умение взаимодействовать с партнером перед и во время соревнований, наличие волевых качеств, мышечной памяти (Верхошанский 1987, Захарьева 2019, Кабачкова 2015). В настоящее время одной из актуальных проблем, которая стоит перед танцорами высокой спортивной квалификации - проблема преодоления стресса и психоэмоционального напряжения на соревнованиях (Андреев 2013). Успешность выступления спортсмена-танцора на соревнованиях во многом зависит от его психоэмоциональной устойчивости. Негативные влияния стресса в спортивных бальных танцах приводят к ухудшению качества исполнения танца, рассогласованию синхронизации между партнером и партнершей, дисритмии внутри пары (Баевский 2008, Беленко 2010). В научной литературе, которая анализировалась нами, практически отсутствуют работы спортивных физиологов по оценке функционального состояния танцоров высокой квалификации, занимающихся спортивными бальными танцами. Имеются лишь не многочисленные работы спортивных психологов по оценке психоэмоционального напряжения у спортсменов - танцоров. Исследованиями Васильевой Н.В. и Козиной М.А. (Васильева, Козина 2015), работающими в Национальном Университете П.Ф. Лесгафта, установлено, что при диагностике психоэмоционального напряжения у танцоров - юниоров с высокими результатами достижений характерна личностная зрелость и самостоятельность, высокая самооценка, низкий уровень нервно - психического напряжения, конструктивные копинг - стратегии. У танцоров - юниоров с низким уровнем достижений имеется склонность к внутренним конфликтам и самообвинениям, что может быть следствием неудовлетворенности собой и своими результатами на соревнованиях. Их отличает пресыщенность рутинной деятельностью на тренировках, необходимость волевого контроля для осуществления деятельности, а также признаки выраженного нервно-психического напряжения.

А.Н. Лысакова и М.С. Новицкая (Льсакова, Новицкая 2014) подчеркивают в своих исследованиях высокий уровень нервно-психического напряжения в мотивации при занятиях спортивными бальными танцами. В научных статьях А.Н. Лысаковой и М.С. Новицкой (Лысакова, Новицкая 2014) дается объективная характеристика танцевальному спорту, как «...очень эмоциональному», а спортивная деятельность на соревнованиях по танцевальному спорту характеризуется как связанная с высокими спортивными психическими нагрузками. Одним из факторов психологического стресса авторами правильно указана субъективная система судейства в танцевальном спорте, которая еще не вышла на объективный уровень оценки исполнения танца, что приводит к дополнительному напряжению нервной системы спортсменов - танцоров. 
Е.С. Моисеев (Моисеев 2014) анализирует психоэмоциональное состояние участников конкурсов бальных спортивных танцев описывает физиологические трансформации в организме спортсменов - танцоров на соревнованиях при воздействии новой пространственной обстановки и влияние «...рецепторной ориентировки на адаптационную способность спортсменов-танцоров», что выражается в психоэмоциональном напряжении. Особо подчеркнуты исследования эмоционального статуса человека в работах датского ученого К.Г. Ланге и американского врача - исследователя В. Джеймса (теория эмоций Ланге-Джеймса), что появление психоэмоциональных переживаний в организме человека приводит к следующим явлениям: к расширению или сужению сосудов, к дискоординации, затормаживанию движений, или двигательной возбужденности, изменения (ускорению/замедлению) ЧСС.

При анализе психологических механизмов возникновения эмоций мы обращались к работам зарубежных психологов, и выявили положение, что эмоции всегда порождают физиологические трансформации в организме человека. Эти знания могут быть использованы в области спортивных бальных танцев, чтобы управлять психоэмоциональным состоянием спортсменов для повышения физиологической эффективности участия в конкурсах.

Согласно ежедневным годичным наблюдениям Е.С. Моисеева (Моисеев 2014) за тренировками в классах хореографии, средний уровень эмоциональной напряженности повышает эффективность деятельности. Обычно это свойственно периоду заблаговременной подготовки спортсменов к соревнованиям. В то же время, отмечено, что низкий или очень высокий уровень эмоционального напряжения, напротив, снижают эффективность соревновательной деятельности. Высокий уровень эмоционального напряжения влечет такие особенности поведения как скованность движений, мышечное напряжение, инертность, заторможенность психических процессов, хаотичность движений (суетливость) и несдержанность в процессе общения.

Сильная эмоциональная напряженность первым делом диссоциирует наиболее сложные формы целеустремленных действий, резко снижается способность к их планированию, к оценке и прогнозированию.

Психологами отмечены негативные влияния малого эмоционального напряжения человека, что выражается в недостаточном включении физиологических механизмов адаптации, ухудшении внимания (феномен сужения внимания) и ухудшении концентрации на нужном объекте. Когда сужение внимания происходит ниже допустимого порога происходит формирование резкого ухудшения внимания и невнимательности. Неполезные для человека трансформации поведения и деятельности случаются и при появлении негативных, в том числе и аффективных (субъективно преувеличенных) переживаний, которые проистекают из неудовлетворенности индивидуально важными потребностями или противоречиями между таковыми. Признаками такого состояния выступает неадекватность мышления, поведения, самооценки, что проявляется в неверном определении задач после неуспеха, поведенческой нестабильности и не предсказуемости, костности мышления, утрате контроля над собой.

Одной из актуальных проблем, которая стоит перед всеми спортсменами, в том числе и танцорами высокой спортивной квалификации - проблема преодоления стресса и сильного психоэмоционального напряжения на соревнованиях (Базарин 2016, Васильева 2015, Волкова 2018, Ханин 1983, Kellmann 2010). Современный танцевальный спорт многие специалисты определяют, как «... очень эмоциональный» 
(Лысакова 2014). Успешность выступления спортсмена-танцора на соревнованиях во многом зависит от его психоэмоциональной устойчивости (Захарьева 2020). Одним из значимых факторов развития высокого психоэмоционального напряжения спортсменов-танцоров является субъективная система судейства, воздействие новой пространственной обстановки и влияние «... рецепторной ориентировки на адаптационную способность спортсменов», а также психоэмоциональное состояние партнеров (Жаворонкова 2006). В зависимости от степени выраженности эмоционального фона спортсмена-танцора могут быть как полезные, так и негативные трансформации эмоционального фона соревнующегося спортсмена, что сказывается на координации движений, точности рефлекторных реакций, гармоничного выступления пары и качестве исполнения танца в целом (Баевский 2008, Верхошанкий 1987, Жаворонкова 2006, Захарьева 2020, Монахова 2017). Изучение влияния психоэмоционального напряжения на функциональное состояние и физические качества танцоров, занимающихся спортивными бальными танцами, имеет большие перспективы в спортивной физиологической науке, так как способствует ранней диагностике качества адаптационного потенциала организма спортсмена.

Для спортивных бальных танцев, так как они организованы парами, очень важно, чтобы психоэмоциональное состояние одного партнера находило отражение в другом. Поэтому неадекватность поведения одного из партнеров влечет защитные действия другого партнера, что только усугубляет аффективность реакции, и оказывает разрушительное воздействие на поведение и выполнение соревновательной нагрузки парой.

Таким образом, при анализе литературных источников установлено, что в зависимости от степени выраженности эмоционального фона спортсмена-танцора могут быть как полезные, так и негативные трансформации эмоционального фона соревнующегося спортсмена, что сказывается на координации движений, точности рефлекторных реакций, гармоничного выступления пары и качестве исполнения танца в целом.

Цель исследования: выявить различия психофизиологических характеристик и физических качеств у танцоров и танцовщиц с различным уровнем психоэмоционального напряжения в подготовительном периоде спортивной подготовки.

\section{Методы}

В исследовании приняли участие 96 спортсменов-танцоров (50 мужчин и 46 женщин), высокой квалификации: 1 взрослый - 58 чел.; КМС (кандидат в мастера спорта) - 24 чел.; МС (мастер спорта) - 13 чел.; 1 чел. - МСМК (мастер спорта международного класса). Средний возраст испытуемых - 20,4 $\pm 5,3$ лет. Стаж занятий спортивными бальными танцами (СБТ) в среднем составил 14,1 6,5 лет. Все процедуры, выполненные в исследованиях с участием людей, соответствуют этическим стандартам национального комитета по исследовательской этике и Хельсинкской декларации 1964 года и ее последующим изменениям или сопоставимым нормам этики. От каждого из включенных в исследование участников было получено информированное добровольное согласие на проведение тестирования. Психофизиологические характеристики танцевальных пар были определены с помощью программно-аппаратного комплекса ИВПС 2.1. (Корягина 2013), тестирование включало в себя 10 тестов, позволяющих судить о восприятии пространственно-временных стимулов и об особенностях организации рефлекторной деятельности испытуемых. Согласно 
результатам исследования: анкетирование, тесты Дж. Тейлора, Ч.Д. Спилбергера Ю.Л. Ханина, «Индивидуальная минута», танцоры были распределены по психоэмоциональному напряжению (ПЭН) на 3 группы: Gr1 - низкий уровень ПЭН (n=40; муж - 24 чел. и жен - 16 чел.); Gr2 - средний уровень ПЭН (n=39; муж - 19 чел. и жен - 20 чел.); Gr3 - высокий уровень ПЭН (n=17; муж - 7 чел. и жен - 10 чел.).

Исследование проводилось в подготовительном периоде спортивной подготовки. Использовались методы: 1. Анкетирование спортсменов, включающее в себя следующие аспекты: возраст испытуемых, стаж занятий, заболеваемость, объем тренировочной нагрузки в неделю/месяц. Анкета № 2: анализ технико-тактических ошибок (удержание основного темпа и ритма, искажение линий корпуса, нарушение работы стоп, нарушение музыкальности, нарушение направлений движений во время исполнения танца, нарушение тактического мышления во время выступления); 2. Чувствительность к психоэмоциональному напряжению определяли временем индивидуальной минуты и оценкой личностной тревожности по результатам теста Джанет Тейлор (TMAS) с использованием компьютеризированного опросника, содержащего 100 утверждений, касающихся состояния, самочувствия и поведения человека в различных повседневных ситуациях. Выделяли уровни тревожности: низкий (до 14,9 баллов), средний (от 15 до 24,9 баллов) или высокий (от 25 баллов); 3. Личностная и ситуативная тревожность определялась тестом Ч.Д. Спилбергера-Ханина; 4. Физическая работоспособность оценена по результатам 2-х ступенчатого теста $\mathrm{PWC}_{170}$ на велоэргометре; 5. Сила мышц кисти и точность мышечных усилий (ТМУ) оценивались методом кистевой динамометрии; 6. Гибкость оценивалась при выполнении шпагата (учитывалось расстояние до пола (см)), и пробой наклона на скамье (см); 7. Психофизиологические характеристики танцоров изучались с использованием компьютерной программы ИВПС 2.1. Тестирование включает в себя 10 тестов, позволяющих судить о восприятии пространственно-временных стимулов, об особенностях организации рефлекторной деятельности испытуемых и косвенно об уровне ловкости; 8. Методы математической статистики, с применением программы Microsoft Office Excel - использовался встроенный статистический пакет «Анализ данных». Вычислялись средние арифметические значения и стандартные отклонения. Для оценки достоверности различия средних значений параметров в выборках проводилось попарное сравнение групп (Gr1, Gr2, Gr3) на основе критериев Манна-Уитни-Уилкоксона, а также сравнение всех трех групп на основе применения критерия Краскела-Уоллиса. Точечные полезные модели распределений, подтверждающие значимость различий по ряду показателей для сопоставляемых выборок, построены с использованием инструмента «Диаграммы» программы Microsoft Office Excel. Часть расчетов проводилась в Rstudio, графики построены с помощью пакета ggplot. На графиках уровни значимости различий имеют обозначения: ns - различие недостоверно; * $-\mathrm{p}<0,05 ; * *-\mathrm{p}<10^{-2} ; * * *-\mathrm{p}<10^{-3} ; * * * *-\mathrm{p}<10^{-4}$.

\section{Результаты}

Проведено обследование 96 танцоров (50 мужчин и 46 женщин) высокой квалификации (от I взрослого разряда до мастеров спорта международного класса). Танцоры регулярно тренируются, и принимают участие в соревнованиях различного уровня (региональные, всероссийские, международные). Средний возраст спортсменов 20,4 $\pm 5,3$ 
лет. Стаж занятий СБТ в среднем составил $14,1 \pm 6,5$ лет. Физиологическое тестирование проведено в подготовительном периоде спортивной подготовки 09.09.201910.12.2019 с 9 до 12 ч. на базе Центра Спортивной Медицины научно-исследовательского института Спорта и Спортивной Медицины РГУФКСМиТ (ГЦОЛИФК).

По результатам теста J. Taylor выделены три группы танцоров с различной степенью психоэмоционального напряжения (ПЭН). Количество баллов теста J. Taylor статистически достоверно отличаются у всех пар групп с уровнем значимости $\mathrm{p}<10^{-}$ ${ }^{4}$ (таблица 1). Первая группа (Gr1) - 40 чел. (41,7 \%) - низкий уровень ПЭН, (среднее

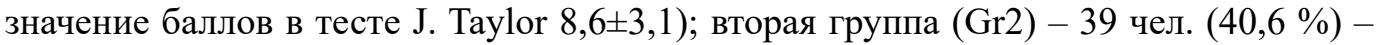
средний уровень ПЭН (среднее значение баллов в тесте J. Taylor - 19,7 $\pm 2,7$ ); третья

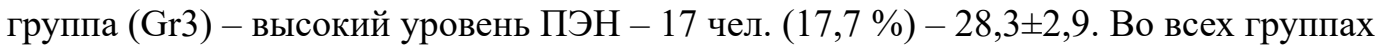
сравнения распределение танцоров по квалификации было сопоставимым: около 50 \% составляли танцоры с I взрослым разрядом; 30 \% - КМС; 20 \% - МС. Спортсмен МСМК входил в 1-ю группу.

Выявлена высокая степень достоверности межгрупповых отличий без учета половых различий в трех группах сравнения в тесте Дж. Тейлора $\left(\mathrm{p}<10^{-4}\right)$ (таблица 1$)$.

Танцоры выполняли психофизиологическое тестирование в программе «Исследователь временных и пространственных свойств человека, версия 2.1». Значимым психофизиологическим тестом, выявляющим отличия в группах сравнения танцоров СВК без учета половых особенностей с различной степенью ПЭН в подготовительном периоде спортивной подготовки, является тест «Реакция на звук», выполненный правой рукой (мс) (таблица 1). В этом тесте достоверно различаются Gr2 и Gr3 (p <0,01).

Таблица 1

Показатели психофизиологического тестирования танцоров высокой квалификации с различной степенью психоэмоционального напряжения

\begin{tabular}{|c|c|c|}
\hline Группа испытуемых & $\begin{array}{c}\text { Tест Taylor } \\
\text { (в баллах) } \\
\text { М } \pm \sigma\end{array}$ & $\begin{array}{c}\text { Реакция на звук правой рукой (мс) } \\
\qquad \pm \sigma\end{array}$ \\
\hline $\begin{array}{c}\mathrm{Gr} 1 \\
(\mathrm{n}=40)\end{array}$ & $8,6 \pm 3,1^{* * *}$ & $354,8 \pm 29,8$ \\
\hline $\begin{array}{c}\mathrm{Gr} 2 \\
(\mathrm{n}=39)\end{array}$ & $19,7 \pm 2,7^{* * * *}$ & $368,4 \pm 35,2^{* *}$ \\
\hline $\begin{array}{c}\mathrm{Gr} 3 \\
(\mathrm{n}=17)\end{array}$ & $28,3 \pm 2,9^{* * * *}$ & $343,5 \pm 25,2^{* *}$ \\
\hline
\end{tabular}

* Примечание: количество баллов в тесте Таylor статистически достоверно различается у всех пар групп сравнения с уровнем значимости **** - p $<10^{-4}$; в тесте «Реакция на звук правой рукой» достоверно различаются показатели групп Gr2 и Gr3 с уровнем значимости ** $-\mathrm{p}<10^{-2}$.

Среди тестов, оценивающих пространственные и временные свойства нервной системы человека, наибольшая степень достоверности межгрупповых отличий, во всех 3-х группах сравнения, выявлена в тесте «Простая зрительно-моторная реакция» (ПЗМР) на 1-й, 2-й и 8-й попытках теста, причем различия устойчиво сохраняются в начале и конце выполнения задания (таблица 2). Существенность отличий показате- 
лей теста имеет высокую степень достоверности у групп танцоров Gr1 и Gr3 (p <10-3) на 1-й и 8-й попытке. Значимость отличий у групп танцоров Gr2 и Gr3 также подтверждена, но с меньшей степенью достоверности $(\mathrm{p}<0,05)$ на 1-й, 2-й и 8-й попытке.

Таблица 2

\section{Показатели теста простой зрительно-моторной реакции танцоров высокой квалификации с различной степенью психоэмоционального напряжения}

\begin{tabular}{|c|c|c|c|}
\hline \multirow{2}{*}{ Группа испытуемых } & \multicolumn{3}{|c|}{$\begin{array}{l}\text { Простая зрительно-моторная реакция (мс) } \\
\text { М } \pm \sigma\end{array}$} \\
\hline & Попытка 1 & Попытка 2 & Попытка 8 \\
\hline $\operatorname{Gr} 1(n=40)$ & $334,7 \pm 60,2$ & $280,4 \pm 56,9$ & $260,75 \pm 60,95$ \\
\hline Gr2 $(n=39)$ & $314,4 \pm 54,5$ & $269 \pm 49,3$ & $250,49 \pm 40,17$ \\
\hline $\operatorname{Gr} 3(n=17)$ & $280,9 \pm 43,2$ & $260,3 \pm 33$ & $254,71 \pm 47,2$ \\
\hline
\end{tabular}

Все показатели психофизиологического тестирования танцоров в исследованных группах сравнивались с нормативными показателями тестов для взрослых здоровых людей. Необходимо отметить, что скорости и точности ответных рефлекторных реакций, а также показатели психофизиологического тестирования у танцоров высокой квалификации превосходят нормативы взрослых здоровых нетренированных людей.

При сопоставлении балльных оценок теста Дж. Тейлора на основе учета пола испытуемых выявлены достоверные отличия у партнеров и партнерш в группах Gr1 и Gr3, при этом подтверждена гипотеза о более высоких значениях теста, наблюдаемых у партнеров (p>0,05); в Gr2 достоверных различий нет, что говорит о синхронизации уровня тревожности партнеров и партнерш.

Для выявления различий в трех группах применялся односторонний дисперсионный анализ Краскела-Уоллиса. в результате его использования для анализа отличий параметров психофизиологического тестирования танцовщиц, имеющих различную степень психоэмоционального напряжения, выявлены достоверные отличия в трех группах сравнения в тесте: «Реакция на звук» (р <0,001) (таблица 3$)$.

Для оценки пространственно-временных свойств нервной системы танцоров и танцовщиц, проводились психофизиологические тесты, позволяющие оценивать восприятие человеком пространства и времени в реальном режиме, тесты с геометрическими антагонистическими задачами, тесты, позволяющие оценивать ориентацию в пространстве, исследуя движение в трёх плоскостях.

У танцовщиц выявлены достоверные различия $(\mathrm{p}<0,05)$ в психофизиологических тестах, позволяющих оценивать точность восприятия времени, точность ориентирования во времени, т. е. «чувство времени» в трех группах сравнения. Результаты теста «Реакция на звук» у танцовщиц (Gr1, Gr2, Gr3) достоверно отличаются (р $<0,001)$ (рис. 1). Кроме того, подтверждена значимость отличий $(\mathrm{p}<0,05)$ указанных выше участниц исследования в тестах: «Воспроизведение временного интервала со звуковым сигналом» (ошибка в \% по модулю), «Оценка величины углов» (ошибка в \% по модулю) (таблица 3). 


\section{Таблица 3}

\section{Результаты проверки гипотезы об отсутствии значимых различий} между 3 группами танцовщиц по исследуемым признакам посредством использования критерия Краскела-Уоллиса

\begin{tabular}{|c|c|c|c|c|}
\hline Признак & $\begin{array}{c}\text { Группа I } \\
(\mathrm{n}=16)\end{array}$ & $\begin{array}{c}\text { Группа II } \\
(n=20)\end{array}$ & $\begin{array}{c}\text { Группа III } \\
(n=10)\end{array}$ & p \\
\hline Реакция на звук правой рукой, (мс) & $351,6 \pm 6,4$ & $385,4 \pm 8,5$ & $341,8 \pm 5,3$ & 0,001 \\
\hline $\begin{array}{l}\text { Воспроизведение временного интервала } \\
\text { со звуковым сигналом } \\
\text { (ошибка в \% по модулю) }\end{array}$ & $12,8 \pm 1,4$ & $21,1 \pm 4$ & $10,3 \pm 1,6$ & 0,05 \\
\hline $\begin{array}{l}\text { Оценка величины углов } \\
\text { (ошибка в \% по модулю) }\end{array}$ & $9,6 \pm 1,3$ & $15,4 \pm 1,6$ & $9,6 \pm 1,4$ & 0,05 \\
\hline URA 2 этап 8 попытка (кол-во ошибок) & $3,9 \pm 0,6$ & $3,4 \pm 0,4$ & $1,6 \pm 0,5$ & 0,05 \\
\hline URA 3 этап 2 попытка (кол-во ошибок) & $5 \pm 0,4$ & $4,9 \pm 0,4$ & $2,8 \pm 0,8$ & 0,05 \\
\hline
\end{tabular}

Для танцовщиц высокой квалификации выявлены достоверные межгрупповые отличия $(\mathrm{p}<0,05)$ показателей теста умственная работоспособность на 2-ом этапе 8-й попытке и 3-ем этапе 2-ой попытке (таблица 3).

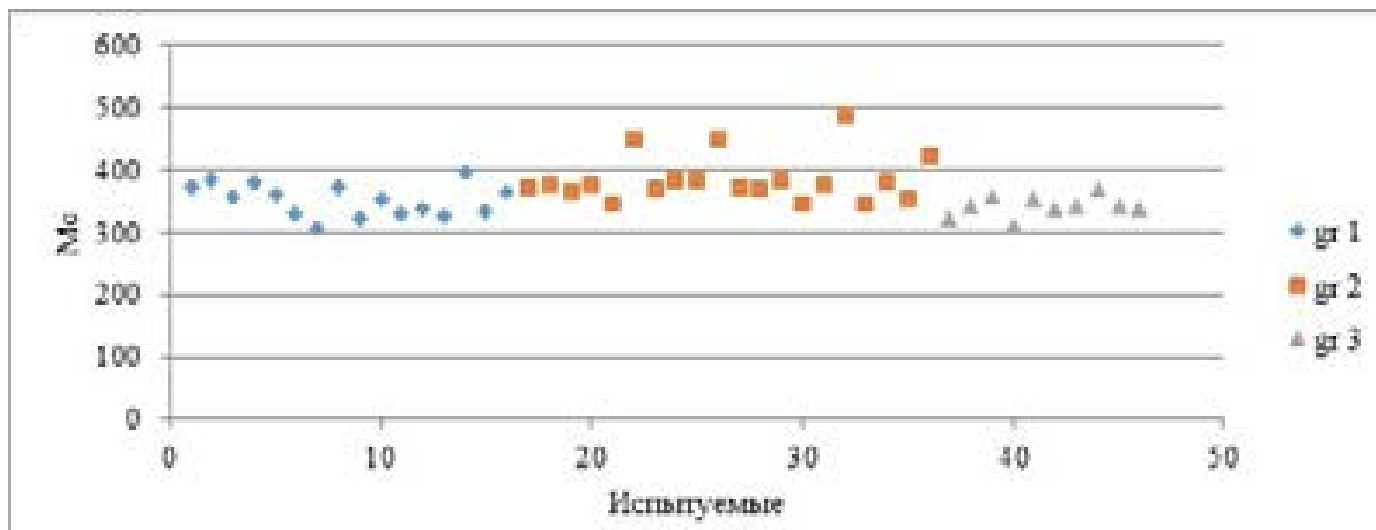

Рис. 1. Распределение танц̧овщий по показателю «Реаки̧ия на звук правой рукой».

У танцоров-мужчин СВК выявлены достоверные различия ( $<<0,05)$ в психофизиологических тестах и физической работоспособности в трех группах сравнения. Это тесты: теппинг тест, попытка 1 и 2; тест отн. $\mathrm{PWC}_{170}$ (таблица 4). Интересно, что у танцовщиц-женщин при применении критерия Краскела-Уоллиса в трех группах сравнения, мы не отмечаем достоверные отличия параметра физической работоспособности. При этом результаты тестирования пространственно-временных свойств нервной системы, позволяющего оценивать точность восприятия времени, точность ориентирования во времени, т. е. «чувство времени» достоверно различны $(\mathrm{p}<0,001)$ в сравнении с танцорами-мужчинами. 
Таблица 4

Результаты проверки гипотезы об отсутствии значимых различий между 3 группами юношей по исследуемым признакам посредством использования критерия Краскела-Уоллиса (в таблице указаны признаки, уровень которых в группах отличается на заданном уровне значимости)

\begin{tabular}{l|l|l|l|l}
\hline Признак & $\begin{array}{l}\text { Группа I } \\
(\mathbf{n = 2 4 )}\end{array}$ & $\begin{array}{l}\text { Группа II } \\
(\mathbf{n = 1 9 )}\end{array}$ & $\begin{array}{l}\text { Группа III } \\
(\mathbf{n = 7 )}\end{array}$ & $\mathbf{p}$ \\
\hline Теппинг тест, интервал 1 (кол-во нажатий) & $16,6 \pm 0,4$ & $18,2 \pm 0,6$ & $19,3 \pm 1$ & 0,05 \\
\hdashline Теппинг тест, интервал 2 (кол-во нажатий) & $17,8 \pm 0,3$ & $18,7 \pm 0,5$ & $21 \pm 1,1$ & 0,05 \\
\hdashline PWС $_{170}$ отн (кгм/мин) & $22,7 \pm 1$ & $20 \pm 0,8$ & $19,1 \pm 0,9$ & 0,05 \\
\hline
\end{tabular}

\section{Обсуждение результатов}

На современном этапе развития танцевального спорта одной из самых значимых проблем, которая стоит перед спортсменами-танцорами, как мужчинами, так и женщинами, является проблема преодоления психоэмоционального напряжения. Развитие психоэмоционального напряжения у спортсменов-танцоров связано со многими причинами: высокими психическими нагрузками на соревнованиях, необходимостью эмоциональной подачей танцевальных программ при исполнении каждого танца, конфликтностью (в паре, с родителями, с тренерами). Особую значимость проблемы развития психоэмоционального напряжения у танцоров составляет необъективность судейства, когда танцевальная пара может быть оценена судьями неоднозначно и доминирующей причиной оценки пары может быть внешний вид спортсменов, принадлежность к танцевальному клубу известного тренера.

Как известно, эмоции всегда порождают физиологические трансформации в организме человека. Согласно теории эмоций Ланге-Джеймса появление психоэмоциональных переживаний в организме человека приводит к сердечно-сосудистому сдвигу: к расширению или сужению сосудов, к дискоординации, затормаживанию движений, или двигательной возбужденности, изменения (ускорению/замедлению) ЧСС. Сильная эмоциональная напряженность первым делом диссоциирует наиболее сложные формы целеустремленных действий, резко снижается способность к их планированию, к оценке и прогнозированию (Ильин 2005). Психологами отмечены негативные влияния малого эмоционального напряжения человека, что выражается в недостаточном включении физиологических механизмов адаптации, ухудшении внимания «феномен сужения внимания» и ухудшении концентрации на нужном объекте. Когда сужение внимания происходит ниже допустимого порога происходит формирование резкого ухудшения внимания и невнимательности. Не полезные для человека трансформации поведения и деятельности случаются и при появлении негативных, в том числе и аффективных (субъективно преувеличенных) переживаний, которые проистекают из неудовлетворенности индивидуально важными потребностей или противоречиями между таковыми. Признаками такого состояния выступает неадекватность мышления, поведения, самооценки, что проявляется в неверном определении задач после неуспеха, поведенческой нестабильности и не предсказуемости, костности мышления, утрате контроля над собой (Реан 2015). 
В спортивной физиологии и педагогике многие ученые выделяют показатели изменения функционального состояния стресс-реакций: выраженная мышечная скованность, сопровождаемая резким понижением координации движений; изменение позы; мимические проявления, (например, выражение глубокого горя); хоботковый рефлекс (губы вытянуты вперед трубкой, подергивание нижней губой с выпячиванием вперед); неадекватные поведенческие реакции; явная ошибочная оценка той или иной информации; ошибочные решения; выраженное нарушение ритма сердечных сокращений и дыхания; уменьшение или увеличение сахара в крови; повышение или понижение АД; длительный и обильный пот, особенно на шее, висках, за ушами, между лопатками; частые позывы на дефекацию; диурез на психогенной основе (Захарьева 2020).

В семиотике психоэмоционального напряжения (ПЭН) человека Т.А. Немчин (Немчин 1983) выделяет в качестве значимых следующие симптомы: 1. Наличие физического дискомфорта; 2. Наличие болевых ощущений; 3. Температурные ощущения; 4. Состояние мышечного тонуса; 5. Координация движений; 6. Состояние двигательной активности в целом; 7. Ощущения со стороны сердечно-сосудистой системы; 8. Проявления со стороны желудочно-кишечного тракта (ЖКТ); 9. Проявления со с стороны органов дыхания; 10. Проявления со стороны выделительной системы. Все эти симптомы могут быть 3-х степеней выраженности: от легкой (I степень ПЭН), средней выраженности (II степень ПЭН), до сильной степени выраженности (III степень ПЭН) и патологических симптомов дисфункции функциональных систем (IV степень ПЭН).

Как показали данные литературных источников, успешность выступления спортсмена-танцора на соревнованиях во многом зависит от его психоэмоциональной устойчивости [9]. Поэтому значимым для спортивной физиологии и педагогики является вопрос раннего выявления танцоров с высоким психоэмоциональным напряжением и его эффективная коррекция педагогическими, медико-биологическими, психологическими и другими средствами. В танцевальном спорте, по результатам нашего многолетнего наблюдения и данных анкетирования, сильное психоэмоциональное напряжение приводит к многочисленным технико-тактическим ошибкам: ухудшению основного ритма и темпа движений, искажению линий корпуса, ухудшению работы стоп, ухудшению музыкальности исполнения движений, нарушению баланса на опорной ноге во время движения. Негативные влияния стресса в спортивных бальных танцах приводят к ухудшению качества исполнения танца, рассогласованию синхронизации между партнером и партнершей, дисритмии внутри пары (Захарьева 2020). Кроме того, отмечено, что при высоком психоэмоциональном напряжении ухудшается тактическое мышление спортсменов - танцоров, а именно, тактическая расстановка своего движения по паркету, так как при исполнении танца опытные и успешные спортсмены-танцоры заранее рассчитывают место и траекторию своего движения, чтобы избежать столкновений с другими участниками соревнований и специально занять выгодное положение на танцевальной площадке, чтобы обеспечить хорошую видимость своего выступления судьям и зрителям.

По результатам обследования 96-ти танцоров высокой квалификации в подготовительном периоде спортивной подготовки установлено, что данные анкетирования, результаты теста J. Taylor и теста «Индивидуальная минута», позволили выделить 3 группы танцоров СВК с различным уровнем психоэмоционального напряжения, со- 
поставимые по стажу, спортивной квалификации, заболеваемости, объему физической нагрузки на тренировках и соревнованиях. На основании данных, полученных в ходе научного эксперимента, установлены психофизиологические тесты, имеющие высокую достоверность в группах сравнения женщин танцовщиц и мужчин-танцоров с различной степенью выраженности психоэмоционального напряжения.

Как известно в спортивной танцевальной паре ведущая роль принадлежит партнеру. Танцоры-мужчины СВК, с различным уровнем психоэмоционального напряжения, отмечают достоверные различия $(\mathrm{p}<0,05)$ как психофизиологических тестах, так и физической работоспособности (в тесте $\mathrm{PWC}_{170}$ ) в трех группах сравнения. Интересно, что достоверные различия установлены в первых попытках теппинг-теста (1-ой и 2-ой попытках), т.е. психофизиологического теста с серийными попытками выполнения.

Для различия скорости рефлекторных реакций в подготовительном периоде у женщин-танцовщиц с различным психоэмоциональным напряжением в 3-х группах сравнения по результатам психофизиологического тестирования самая высокая достоверность различий отмечена в тесте «Реакция на звук» $(\mathrm{p}<0,001)$. Меньшая степень достоверности выявлена в психофизиологических тестах, позволяющих оценивать точность восприятия времени, точность ориентирования во времени, т. е. «чувство времени» в трех группах сравнения: «Воспроизведение временного интервала со звуковым сигналом» (ошибка в \% по модулю), «Оценка величины углов» (ошибка в \% по модулю) $(\mathrm{p}<0,05)$. Эти тесты имеют достоверность межгрупповых различий во всех группах сравнения и могут быть рекомендованы для диагностики, дифференцирования уровней психоэмоционального напряжения танцовщиц и раннего выявления высокого психоэмоционального напряжения при занятиях спортивными бальными танцами на этапе высокой квалификации спортсменов в подготовительном периоде спортивной подготовки. Танцовщицы высокой квалификации отмечают достоверные межгрупповые отличия (р $<0,05)$ показателей теста умственная работоспособность на этапах усложнения когнитивных задач: 2-ом и 3-ем этапах соответственно (на 2-ом этапе 8-й попытке и 3-ем этапе 2-ой попытке). Достоверными различиями физической работоспособности в тесте $\mathrm{PWC}_{170}$ танцовщицы с различным уровнем психоэмоционального напряжения в подготовительном периоде спортивной подготовки не отличаются.

\section{Заключение}

Таким образом, в результате проведенного физиологического эксперимента выявлены половые различия психофизиологических характеристик и физической работоспособности танцоров-мужчин и танцовщиц-женщин СВК, занимающихся спортивными бальными танцами в подготовительном периоде спортивной подготовки. Спортсмены-танцоры с различным уровнем психоэмоционального напряжения отличаются показателями физической работоспособности и максимальным произвольным темпом движения кисти. Самым значимым отличием спортсменок-танцовщиц с различным психоэмоциональным напряжением является скорость рефлекторной реакции «Время реакции на звук». Выявленные отличия необходимо использовать для дифференцирования уровней психоэмоционального напряжения танцоров СВК, раннего выявления высокого психоэмоционального напряжения и оптимизации тренировочного процесса танцоров высокой квалификации в подготовительном периоде спортивной подготовки. 


\section{Выводы}

1. Для дифференцирования уровней психоэмоционального напряжения у танцоров высокой квалификации и раннего выявления высоко психоэмоционального напряжения спортсменов и спортсменок в подготовительном периоде спортивной подготовки рекомендованы психофизиологические тесты: J. Taylor; «Реакция на звук правой рукой», (мс); Простая зрительно-моторная реакция (мс) и тест физической работоспособности $\mathrm{PWC}_{170}$.

2. У танцовщиц высокой квалификации для дифференцирования уровней психоэмоционального напряжения в подготовительном периоде спортивной подготовки рекомендованы психофизиологические тесты: «Реакция на звук», выполненная правой рукой (мс) ( $<<0,001)$ в $3-$ х группах сравнения; «Воспроизведение временного интервала со звуковым сигналом» (ошибка в \% по модулю), «Оценка величины углов» (ошибка в \% по модулю) $(\mathrm{p}<0,05)$. Достоверных межгрупповых отличий физических качеств у танцовщиц не выявлено.

3. У танцоров-мужчин высокой квалификации для дифференцирования уровней психоэмоционального напряжения в подготовительном периоде спортивной подготовки рекомендованы: тест определения физической работоспособности $\mathrm{PWC}_{170}(\mathrm{p}<0,05)$ и теппинг-тест (1-я и 2-я попытка).

4. Танцоры, имеющие высокое психоэмоциональное напряжение, имеют самые низкие значения физической работоспособности в группах сравнения, что может обуславливать их низкую результативность на соревнованиях и диктует необходимость включения аэробных физических упражнений в их тренировочный процесс.

\section{Научная литература}

Андреев Р.С. Взаимосвязь характеристик инфракрасного температурного портрета с метаболическими показателями у спортсменов. Диссертация ... кандидата биологических наук. 03.03.01. Москва: Ин-т возраст. физиологии РАО, 2013. 115 с.

Баевский Р.М. Введение в донозологическую диагностику // Баевский Р.М., Берсенева А.П. // M., 2008. $218 \mathrm{c}$.

Базарин К.П. Вклад психоэмоционального напряжения в развитие срыва адаптации в соревновательном периоде у спортсменов высокой квалификации // Базарин К.П., Савченко А.А. // Клиническая медицина Бюллетень ВСНЦ РАМН, 2016. № 32 (108). С. 7-13.

Беленко И.С. Влияние занятий спортом на функциональное состояние нервной и дыхательной систем у юных футболистов и баскетболистов в возрасте 11-15 лет разных соматотипов // И.С. Беленко ...диссертация к.б.н.- г. Майкоп, 2010. 246 с.

Васильева М.А. Особенности нервно-психического напряжения у спортсменов - юниоров при занятиях спортивными бальными танцами / Васильева М.А., Козина Н.В. // Медицинская психология в России № 5 (14). г. Санкт-Петербург, 2015. С. 28-32.

Верхошанский Ю.Е. Некоторые закономерности долговременной адаптации организма спортсмена к физическим нагрузкам / Ю.Е. Верхошанский, Виру А.А. // Физиология человека, 1987. № 5. C. 811-818.

Петровский А.В. (под ред.) Возрастная и педагогическая психология. М. «Просвещение», 1979. 116 с.

Волкова М.Г. Кризисные ситуации в жизни спортсменов - юниоров. Эмпирическое исследование / М.Г. Волкова // Научно-педагогические школы в сфере физической культуры и спорта: Материалы Международного научно-практического конгресса, посвященного 100-летию ГЦОЛИФК, 30-31 мая 2018 г. / под общей ред. А.А. Передельского и др. М.: РГУФКСМиТ, 2018. С. 37-41. 
Вяткин Б.А. Управление психическим стрессом в спортивных соревнованиях. М., 1981. 112 с.

Горска, И.Ю. Специфика моторной подготовленности в разных видах спорта / И.Ю, Горская // Научно-педагогические школы в сфере физической культуры и спорта: Материалы Международного научно-практического конгресса, посвященного 100-летию ГЦОЛИФК, 30-31 мая 2018 г. / под общей ред. А.А. Передельского и др. М.: РГУФКСМиТ, 2018. С. 42-47.

Дюсембаева Б.М. Влияние психологии на успешное выступление спортсменов / Евразийский национальный университет им. Л.Н. Гумилева. Астана, 2013. С. 324-329.

Жаворонкова И.А. Комплектование пар в спортивных бальных танцах (на примере 12-15 лет). Дис... канд. пед. наук 13.00.04: БГУ Белгород, 2006. 148 с.

Захарьева Н.Н., Коняев И.Д. Влияние психоэмоционального напряжения на функциональное состояние танцоров. М.: РГУФКСМиТ, 2020. 293 с.

Захарьева Н.Н. Возрастные особенности типологических характеристик вегетативного баланса юных танцоров. // Материалы V Международной научно-практической конференции: «Актуальные вопросы медико-биологического сопровождения хореографии и спорта» 8-10 апреля 2019 г. СП-б., 2019. С. 198-202.

Ильин Е.П. Психофизиология состояний человека. Санкт- Петербург, 2005. 411 с.

Кабачкова А.В. «Самочувствие - Активность - Настроение» студентов первокурсников при посещении занятий по физической культуре / А.В. Кабачкова // Теория и практика физической культуры, 2015. № 7. С. 29-31.

Корягина Ю.В. Аппаратно-программные комплексы исследования психофизиологических особенностей спортсменов / Ю.В. Корягина, С.В. Нопин // Вопросы функциональной подготовки в спорте высших достижений. Материалы Всероссийской конференции, Омск, 11-12 апреля 2013 г. Т. 1. № 1. С. 70-78.

Льсакова А.Н. Психологические особенности спортивно-танцевальной деятельности // Вестник университета, 2014. № 2. С. 254-258.

Монахова Е.Г. Особенности физической подготовки спортсменов - танцоров // Образование и физическая культура, 2017. № 2. С. 213-217.

Москвин В.А. Психофизиология индивидуальных различий человека / Москвин В.А., Москвина Н.В. М.: Изд-во МИП, 2011. 177 с.

Немчин Т.А. Состояния нервно-психического напряжения. Л.: ЛГУ, 1983. 166 с.

Реан A.A. (под ред.) Психология человека от рождения до смерти. М.: «Издательство АСТ», 2015. $306 \mathrm{c}$.

Ханин Ю.Л. Стресс и тревога в спорте. М.: Физкультура и спорт, 1983. 287 с.

Kellmann M. Preventing over training in athletes in high-in ten sity sports and stress/recovery monitoring // Scand J Med SciSports, 2010. P. 95-102.

Zakharyeva Natalia N., Ilya D. Konyaev, and Irina V. Abdrakhmanova I.V.

The influence of psychoemotional stress on the psychophysiological reactions and physical qualities of highly qualified dancers

\section{DOI: $10.33876 / 2311-0546 / 2021-4 / 381-395$}

Ninety-six highly-qualified dancers (50 males and 46 females) were studied during the preparatory step of sports training. The dancers were tested for psychoemotional stress using the Taylor test, Spielberger-Khanin method, a test of individual time perception, and questionnaires. According to the results, they were divided into three groups: Gr1-low level ( $n=40 ; 24$ males and 16 females); Gr2 - medium level ( $n=39 ; 19$ males and 20 females); Gr3 - high level ( $n=17 ; 7$ males and 10 females). The following psychophysiological tests are recommended to differentiate the levels of psychoemotional stress of highly qualified dancers without taking into account gender differences: Taylor test; "Reaction to an acoustic stimulus with the right hand," (ms); Simple visual-motor reaction (ms) and the PWC170 
physical performance test. In female dancers with different levels of psychoemotional stress, significant differences were found between the compared groups in the tests: "Reaction to acoustic stimulus" with the right hand ( $m s)(p<0,001)$; an acoustic duration reproduction task (mean percentage error), "estimation of angle size" (mean percentage error) $(p<0,05)$. In male dancers with different levels of psychoemotional stress, significant differences were found in the tests: PWC170 $(p<0,05)$ and tapping test (1-st and 2-nd attempts). Dancers with high psychoemotional stress have the lowest physical performance values between the compared groups, which may cause their low performance in competitions.

Keywords: sports ballroom dancing, mental and physical performance, functional state, spatial and temporal characteristics of the nervous system, dancers

For Citation: Zakharyeva N.N., I.D.Konyaev, and I.V. Abdrakhmanova. 2021. The influence of psychoemotional stress on the psychophysiological reactions and physical qualities of highly qualified. Herald of Anthropology (Vestnik Antropologii) 4: 381-395.

Authors info: Zakharyeva Natalia N. - Doctor of medical sciences, Professor. Federal state budgetary educational establishment of higher education «Russian state university of physical education, sport, youth and tourism (SCOLIPE)».E-mail: zakharyeva.natalia@mail.ru

Konyaev Ilya D. - graduate student, Federal state budgetary educational establishment of higher education «Russian state university of physical education, sport, youth and tourism (SCOLIPE) ». E-mail: Ilya.konyaev@mail.ru

Abdrakhmanova Irina V. - Doctor of Pedagogical sciences, Docent. Federal state educational budget institution of higher education «Volgograd state physical education academy». E-mail: abdr-iren@yandex.ru

\section{References}

Andreev, R.S. 2013. Vzaimosvyaz' harakteristik infrakrasnogo temperaturnogo portreta s metabolicheskimi pokazatelyami u sportsmenov. [The relationship of the characteristics of the infrared temperature portrait with metabolic parameters in athletes]. PhD, Diss, Moscow, Institute of Developmental Physiology, Russian Academy of Sciences.

Baevskij, R.M. and A.P. Berseneva. 2008. Vvedenie v donozologicheskuyu diagnostiku [Introduction to prenosological diagnostics]. Moscow.

Bazarin, K.P. and A.A. Savchenko. 2016. Vklad psihoemocional'nogo napryazheniya v razvitie sryva adaptacii v sorevnovatel'nom periode u sportsmenov vysokoj kvalifikacii [The contribution of psycho-emotional stress to the development of adaptation breakdown in the competitive period in highly qualified athletes]. Klinicheskaya medicina Byulleten' VSNC RAMN 32 (108): 7-13.

Belenko, I.S. 2010. Vliyanie zanyatij sportom na funkcional'noe sostoyanie nervnoj i dyhatel'noj sistem $\mathrm{u}$ yunyh futbolistov i basketbolistov v vozraste 11-15 let raznyh somatotipov [The influence of sports on the functional state of the nervous and respiratory systems in young football and basketball players aged 11-15 years of different somatotypes]. Dissertaciya kandidata biologicheskih nauk. Majkop.

Vasil'eva, M.A. and N.V. Kozina. 2015. Osobennosti nervno-psihicheskogo napryazheniya u sportsmenov - yuniorov pri zanyatiyah sportivnymi bal'nymi tancami [Features of neuropsychic stress in junior athletes during sports ballroom dancing]. Medicinskaya psihologiya $v$ Rossii. 5 (14): 28-32.

Verhoshanskij, YU.E and A.A. Viru. 1987. Nekotorye zakonomernosti dolgovremennoj adaptacii organizma sportsmena $\mathrm{k}$ fizicheskim nagruzkam [Some patterns of long-term adaptation of the athlete's body to physical exertion]. Fiziologiya cheloveka 5: 811-818. 
Vozrastnaya i pedagogicheskaya psihologiya. 1979 [Age and educational psychology], edited by A.V. Petrovskogii, Moscow: «Prosveshchenie».

Volkova, M.G. 2018. Krizisnye situacii v zhizni sportsmenov - yuniorov [Crisis situations in the life of junior athletes]. Empiricheskoe issledovanie. V Sb. Nauchno-pedagogicheskie shkoly v sfere fizicheskoj kul tury i sporta: Materialy Mezhdunarodnogo nauchno-prakticheskogo kongressa, posvyashchennogo 100-letiyu GCOLIFK, edited by A.A. Peredeliskogo i dr., 37-41. Moscow: RGUFKSMiT.

Vyatkin, B.A. 1981. Upravlenie psihicheskim stressom v sportivnyh sorevnovaniyah [Managing mental stress in sports competitions]. Moscow.

Gorskaya, I.YU. 2018. Specifika motornoj podgotovlennosti v raznyh vidah sporta [The specifics of motor fitness in different sports]. V Sb. Nauchno-pedagogicheskie shkoly v sfere fizicheskoj kul 'tury i sporta: Materialy Mezhdunarodnogo nauchno-prakticheskogo kongressa, posvyashchennogo 100-letiyu GCOLIFK, edited by A.A. Peredeliskogo i dr., 42-47. Moscow: RGUFKSMiT.

Dyusembaeva, B.M. 2013. Vliyanie psihologii na uspeshnoe vystuplenie sportsmenov [The influence of psychology on the successful performance of athletes]. Evrazijskij nacional'nyj universitet im. L.N. Gumileva, 324-329. Astana.

ZHavoronkova, I.A. 2006. Komplektovanie par v sportivnyh bal'nyh tancah (na primere 12-15 let) [Recruitment of couples in sports ballroom dancing (for example, 12-15 years old)]. $\mathrm{PhD}$ diss. abstract, Belgorod.

Zahar'eva, N.N. and I.D. Konyaev. 2020. Vliyanie psihoemocional'nogo napryazheniya na funkcional'noe sostoyanie tancorov [The influence of psychoemotional stress on the functional state of dancers]. Moscow: RGUFKSMiT.

Zahar'eva, N.N. 2019. Vozrastnye osobennosti tipologicheskih harakteristik vegetativnogo balansa yunyh tancorov [Age-specific typological characteristics of the vegetative balance of young dancers]. In Sb. Materialy V Mezhdunarodnoj nauchno-prakticheskoj konferencii: «Aktual'nye voprosy mediko-biologicheskogo soprovozhdeniya horeografii i sporta» [Materials of the V International scientific and practical conference: "Topical issues of medical and biological support of choreography and sports" April 8-10, 2019], 198-202. St. Petersburg.

Il'in, E. P. 2005. Psihofiziologiya sostoyanij cheloveka [Psychophysiology of human states]. SPb.

Kabachkova, A.V. 2015. «Samochuvstvie - Aktivnost' - Nastroenie» studentov pervokursnikov pri poseshchenii zanyatij po fizicheskoj kul'ture ["Well-being - Activity - Mood" of first-year students when attending physical education classes]. Teoriya i praktika fizicheskoj kul tury 7: 29-31.

Koryagina, YU.V. and S.V. Nopin. 2013. Apparatno-programmnye kompleksy issledovaniya psihofiziologicheskih osobennostej sportsmenov [Hardware and software complexes for the study of psychophysiological characteristics of athletes]. Voprosy funkcional'noj podgotovki $v$ sporte vysshih dostizhenij. Materialy Vserossijskoj konferencii 1 (1): 70-78. Omsk.

Lysakova, A.N. and M.S. Novickaya. 2014. Psihologicheskie osobennosti sportivno-tanceval'noj deyatel'nosti [Psychological features of sports and dance activity]. Vestnik universiteta 2: 254-258.

Monahova, E.G. 2017. Osobennosti fizicheskoj podgotovki sportsmenov - tancorov [Features of physical training of athletes - dancers]. V ZHurnale Obrazovanie i fizicheskaya kul 'tura 2: 213-217.

Moskvin, V.A. and N.V. Moskvina 2011. Psihofiziologiya individual'nyh razlichij cheloveka [Psychophysiology of individual human differences]. Moscow: Izd-vo MIP.

Nemchin T. A. 1983. Sostoyaniya nervno-psihicheskogo napryazheniya [States of neuropsychic tension]. LGU.

Rean, A.A. (ed.) 2015. Psihologiya cheloveka ot rozhdeniya do smerti [Human psychology from birth to death]. Moscow: «Izdatel'stvo AST».

Hanin, YU.L. 1983. Stress i trevoga v sporte [Stress and anxiety in sports]. Fizkul'tura i sport: 287.

Kellmann, M. 2010. Preventing over training in athletes in high-in ten sity sports and stress/recovery monitoring. Scand J Med SciSports: 95-102. 